\title{
Screening for anaemia: evaluation of a haemoglobinometer
}

\author{
A F MILLS* AND N MEADOWS $\dagger$ \\ *Department of Community Paediatrics; Waltham Forest Health Authority, and + Department of Paediatrics, \\ Whipps Cross Hospital, London
}

SUMmaRY The HemoCue haemoglobinometer was evaluated as part of a programme to screen children aged 11-36 months for anaemia when they attended a routine immunisation clinic. Paired capillary blood samples were collected and measured on the haemoglobinometer and on a Coulter counter model S. Measurements made from bottle collected capillary samples were more precise than those made from single drops of blood. After compensation for a fixed bias the haemoglobinometer had a sensitivity of 0.85 and a specificity of 0.94 when used to detect anaemia.

Careful attention must be paid to the method of blood collection. We suggest that cuvettes are filled from bottle collected capillary samples rather than single blood droplets taken direct from the finger. The haemoglobinometer was reliable, simple to use with the minimum of training, and proved to be suitable for use in a community child health clinic.

Iron deficiency anaemia in children retards the attainment of developmental milestones, causes growth to slow down, and increases the risk of infection. ${ }^{12}$ These factors have led to calls for routine screening for anaemia in infants. ${ }^{3-5}$ The ability to measure haemoglobin concentration quickly, accurately, and with minimal trauma will form an important part of any screening programme.

The HemoCue haemoglobinometer (Clandon Scientific) is a portable machine that measures haemoglobin by photometric assay with disposable plastic cuvettes. Only $10 \mu \mathrm{l}$ of blood is required and the result is shown on a liquid crystal display within 60 seconds. It is accurate and precise when used on mixed venous blood in laboratory conditions. ${ }^{6}$

This study was designed to evaluate the system in an infant welfare clinic using finger prick blood samples.

\section{Subjects and methods}

Parents of children aged 11 to 36 months attending four different immunisation clinics in east London were invited to participate in a programme to screen their child for anaemia. Parents were approached on arrival at the clinic and were given a short verbal and written description of the test. The verbal information was always given by the same person (AFM).
Translators were present, and the written description was available in English, Urdu, Bengali, Punjabi, and Gujarati. The screening test was always undertaken after immunisation.

Finger prick blood was sampled using a spring loaded lancet device (Autolet). No preparation (such as warming the finger) was necessary. This blood was collected into a $1.8 \mathrm{ml}$ bottle containing edetic acid. A cuvette was filled directly from the finger (direct method) and a second cuvette was filled from the specimen in edetic acid after it had been carefully agitated (bottle method). Cuvettes were measured immediately they had been filled. The remainder of the specimen in edetic acid was sent for routine laboratory analysis on a Coulter counter ' $S$ ' at the Whipps Cross Hospital haematology laboratory.

Results that were below the $95 \%$ reference range for haemoglobin concentration $(<110 \mathrm{~g} / \mathrm{l})$ were classified as anaemic. ${ }^{7}$

Standardisation of the HemoCue to the Coulter counter was checked during the study using four laboratory standards (range 83-114 g/l). Two cuvettes were measured from each standard. This indicated a mean (SEM) positive bias of $1.4(0.9) \mathrm{g} / \mathrm{l}$. The $95 \%$ confidence interval was $5.1 \mathrm{~g} / \mathrm{l}$ above and below the mean. Calibration was checked daily using a control cuvette and was never found to vary by more than 
$1 \mathrm{~g} / \mathrm{l}$ above or below the mean. No recalibration was undertaken during the course of the study.

Accuracy was measured for each method by calculating the mean and standard deviation of differences between results from bottle method and Coulter counter or direct method and Coulter counter. ${ }^{8}$ The mean was a measure of bias, and the $95 \%$ precision range was the mean plus or minus 1.96 multiplied by the standard deviation.

If children were found to be anaemic they were referred for further assessment and follow up.

Approval was obtained from both hospital and district ethics committees.

\section{Results}

Of those offered the test, $65 \%$ agreed to be investigated.

A total of 102 samples measured by both direct and bottle methods and Coulter counter were collected. Figs 1 and 2 show the accuracy and precision of each method. Both methods show a positive bias of between 3 and $4 \mathrm{~g} / \mathrm{l}$, but the bottle method was more precise.

There was no significant difference in the precision of either method in the first half of the study compared with the second half. Experience of the operator was therefore not a factor.

Table 1 shows the sensitivity and specificity of the

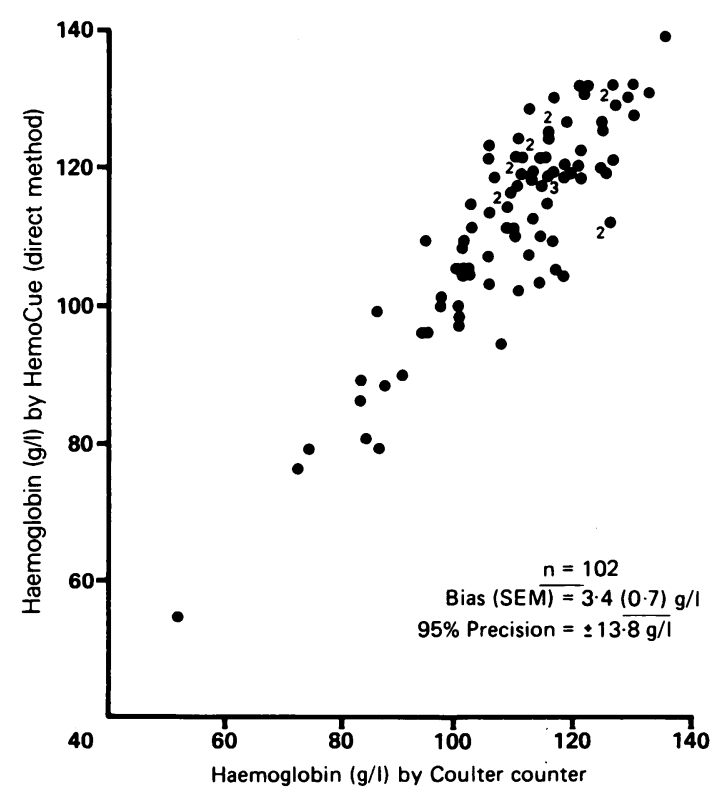

Fig 1 Haemoglobin concentration measured by HemoCue after direct collection and by Coulter counter ' $S$ '.

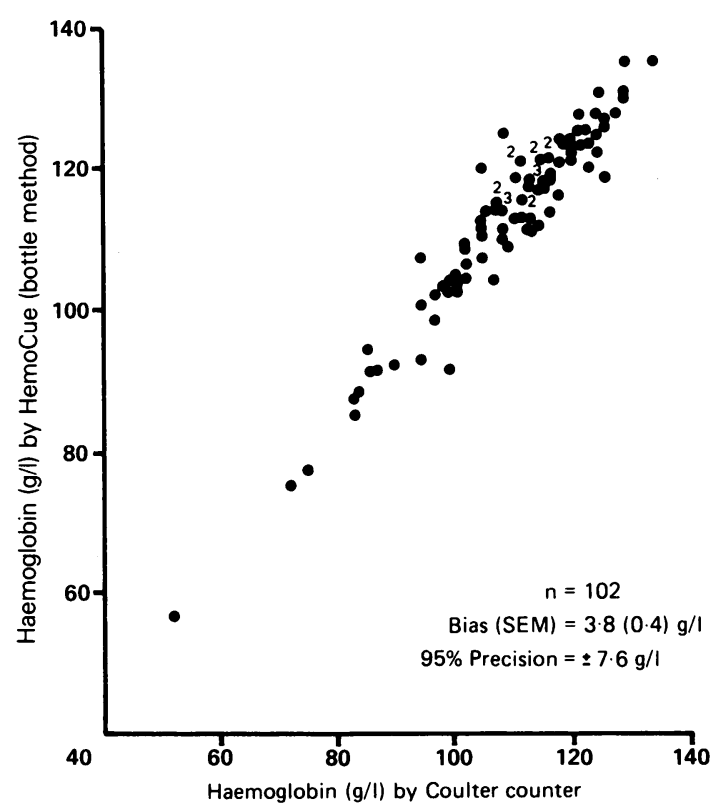

Fig 2 Haemoglobin concentration measured by HemoCue after bottle method collection and by Coulter counter ' $S$ '.

Table 1 Validity of each method before and after correction for bias

\begin{tabular}{|c|c|c|}
\hline \multirow{2}{*}{$\begin{array}{l}\text { Method of } \\
\text { collection } \\
\text { of blood }\end{array}$} & \multicolumn{2}{|l|}{ Validity } \\
\hline & $\begin{array}{l}\text { Sensitivity } \\
\text { (proportion of } \\
\text { cases correctly } \\
\text { classified anaemic) }\end{array}$ & $\begin{array}{l}\text { Specificity } \\
\text { (proportion of } \\
\text { cases correctly } \\
\text { classified healthy) }\end{array}$ \\
\hline Direct & 70 & 90 \\
\hline Direct, corrected & 80 & 82 \\
\hline Bottle & 75 & 100 \\
\hline Bottle, corrected & 85 & 94 \\
\hline
\end{tabular}

Correction for bias $=-4 \mathrm{~g} / \mathrm{l}$ from each HemoCue result.

methods in both healthy and anaemic patients. The effect of compensation for bias by subtracting $4 \mathrm{~g} / 1$ from each HemoCue result is shown. Table 2 shows the detailed results using the bottle method compensated for bias.

Haemostasis was achieved easily by pressing on a clean paper tissue. Adhesive plasters were not used because of concern that young children might swallow them.

There were no complications after the finger prick. The investigation was well received by parents. The haemoglobinometer was simple to use, easily 
Table 2 Results using bottle method, corrected for bias

\begin{tabular}{|c|c|c|c|}
\hline \multirow{2}{*}{$\begin{array}{l}\text { HemoCue } \\
\text { results }\end{array}$} & \multicolumn{2}{|l|}{ Coulter results } & \multirow[t]{2}{*}{ Tota } \\
\hline & $\begin{array}{l}\text { Anaemic } \\
\text { (haemoglobin } \\
<110 \mathrm{~g} / \text { l) }\end{array}$ & $\begin{array}{l}\text { Healthy } \\
\text { (haemoglobin } \\
\geqslant 110 \mathrm{~g} / \mathrm{l})\end{array}$ & \\
\hline $\begin{array}{l}\text { Anaemic } \\
\text { (haemoglobin } \\
<110 \text { g/l) }\end{array}$ & 34 & 4 & 38 \\
\hline $\begin{array}{l}\text { Healthy } \\
\text { (haemoglobin } \\
\geqslant 110 \mathrm{~g} / \text { ) }\end{array}$ & 6 & 58 & 64 \\
\hline Total & 40 & 62 & 102 \\
\hline
\end{tabular}

portable, and reliable. No machine failure occurred during the study.

\section{Discussion}

A high percentage of the population served by Waltham Forest health authority originate from India and Pakistan. There is much social deprivation. A previous study from this health authority found a prevalence of iron deficiency anaemia of $25 \%$ in 1 year old Asian children. ${ }^{9}$ A campaign to find and treat iron deficiency anaemia was therefore considered a priority for the community paediatric service.

Any screening test should be accurate (with a low number of false positives and false negatives), acceptable, and inexpensive. Unfortunately, no single investigation can reliably separate all those with and without iron deficiency. Haemoglobin concentration is the most conveniently measured variable, although the high incidence of haemoglobinopathies in some groups complicates this. A haemoglobin concentration of less than $110 \mathrm{~g} / \mathrm{l}$ was regarded as an indication for further assessment. ${ }^{7}$

The use of single finger prick samples (direct method) was found to be unacceptably imprecise. The large variation in finger prick sample values compared with results from the Coulter counter was probably caused by rouleaux formation and haemodilution at the finger tip. The measurement of capillary blood collected in a bottle seemed to compensate for these errors and considerably improved accuracy without adding to technical difficulty. This technique makes the rapid and accurate measurement of haemoglobin possible in a busy clinic.

An important error was a fixed positive bias which significantly reduced accuracy. The HemoCue operating manual recommends the use of a single standard specimen to check the calibration, in addition to daily use of the control cuvette provided. In this study four standard samples were used. This calibration did not uncover the bias that was subsequently noted over 102 pairs of specimens. A spontaneous change in the performance of the haemoglobinometer is unlikely to explain this observation, as at no time did the control cuvette indicate a change in calibration. The reason this bias was undetected was probably the small number of standardisation measurements used, as both the HemoCue and Coulter counter have operating errors. To allow for this we recommend that initial calibration should be made using at least 30 measurements from a number of standard specimens with a wide range of values. ${ }^{8}$ The mean difference between HemoCue results and sample values will indicate the machine bias, which can then be recalibrated accordingly. The control cuvette is then measured on the machine and its value redesignated. Subsequent quality control needs to be monitored regularly.

After adjustment for bias, the bottle method correctly classified $85 \%$ of the anaemic and $94 \%$ of the healthy cases. The use of the bottle method makes further investigation easier by collecting a specimen that can be sent for analysis if the haemoglobin concentration is low on first screening.

Taking finger prick samples with a spring loaded lancet was simple and caused minimal upset. For a routine screening test, capillary blood sampling has considerable advantages over venepuncture. The speed and ease of a finger prick sample is likely to ensure satisfactory uptake. Venepuncture in infants is often technically difficult, more time consuming, and usually requires two members of staff. A technique that only requires a single operator clearly has advantages in any service constrained by lack of funds or personnel.

It is difficult to estimate the cost of a screening programme such as this. The haemoglobinometer cost $£ 434$, and each microcuvette costs $25 p$ and can be used only once. Additional costs will be that of bottles containing edetic acid and the lancets. Greater expense will be for doctors' time, and the expense of follow up investigations and counselling. The fact that only one person is needed to administer the test makes it attractive, and the immediate availability of results means that counselling and possibly treatment can be started at the same interview. This saved considerable administrative time and was popular with parents.

It has been stressed that equipment intended for primary health care should be evaluated under normal working conditions. ${ }^{6}$ This study evaluated the HemoCue in the sort of clinic in which it will be used. It is robust, portable, and simple to use. It 
operates on rechargeable batteries and therefore does not need a power socket. Careful attention must be paid to methods of collecting blood and calibrating the machine for optimal accuracy.

We conclude that the collection of blood into a bottle for a mixed sample, rather than direct filling from the finger prick, is more accurate and reliable. The HemoCue is a useful instrument for the routine screening of children for iron deficiency anaemia within the community paediatric service although those found to be anaemic require clinical assessment, precise laboratory diagnosis, and careful follow up.

We thank Dr C D'Silva and the medical laboratory scientific officers from Whipps Cross Hospital haematology department for analysing Coulter specimens and for assistance with calibration. Mr J Clegg of Clandon Scientific. Mrs Inda Ford for translation. and Dr P Thompson for advice and encouragement.

\section{References}

1 Aukett MA, Parks YA. Scott PH, Wharton BA. Treatment with iron increases weight gain and psychomotor development. Arch Dis Child 1986;61:849-57.

2 Lozoff B. Brittenham GM. Wolf AW, et al. Iron deficiency anaemia and iron therapy: effects on infant developmental test performance. Pediatrics 1987:79:981-95.

3 Illingworth RS. Anaemia and child health surveillance. Arch Dis Child 1986;61:1151-2.

+ Addy DP. Happiness is: iron. Br Med J 1986;292:969-70.

s Editorial. Iron deficiency-time for a community campaign? Lancet 1987:i:141-2.

- Neville RG. Evaluation of portable haemoglobinometer in general practice. Br Med J 1987;294:1263-5.

7 Dallman PR. Reeves JD. Laboratory diagnosis of iron deficiency. In: Stekel A, ed. Iron nutrition in infancy and childhood. Nestlē Nutrition Workshop Series, Vol 4. New York: Raven Press, 1984.

* Altman DG. Statistics and ethics in medical research. In: Gore SM. Altman DG, eds. Statistics in practice. London: British Medical Association, 1982:1-24.

${ }^{y}$ McEnery G, Rao KPS. The effectiveness of antenatal education of Pakistani and Indian women living in this country. Child Care Health Dev 1986;12:385-99.

Correspondence to Dr AF Mills, Insurance House, Insurance Street, Islington, London WCIX 0JB.

Accepted 9 March 1989 